\title{
My Thought on Rabies in the Democratic Republic of Congo
}

\author{
Trésor Bodjick Muena Mujobu*
}

Clinical Pharmacology Unit/National Pharmacovigilance Center, University of Kinshasa, Kinshasa, Democratic Republic of Congo

\author{
Received: January 02, 2016; Accepted: January 12, 2016; Published: January 20, 2016
}

*Corresponding author: Trésor Bodjick Muena Mujobu, MD, M.Sc, Clinical Pharmacology Unit/National Pharmacovigilance Center, University of Kinshasa, Kinshasa, Democratic Republic of Congo, Tel : +243-819-792-529 ; E-mails : tresor.bodjick@gmail.com

The Democratic Republic of Congo, DR Congo,lies in the heart of Africa and is the second largest country of the continent [1]. According to the World Health Organization, the risk for humans contacting Rabies in this country is high (Figure 1). Moreover, due to poor surveillance and under-reporting, the incidence of Rabies could be 160-times official reports [2].

Two months ago, my youngest sister was bitten by a dog. The dog belongs to a family we share friendly relationship with. This was frightening for the entire family since the dog's owner claimed $t$ it was vaccinated against Rabies but could not produce any reliable certificate from the veterinary services. Dogs are indeed the main reservoirs and vectors for the Rabies virus in this part of the world [3]..

I went to see the public health service to get information about the cost of Rabies immunoglobulins and Rabies vaccine, as well as the vaccine quality. The vaccines they have consists of rabies virus that has been propagated in cell substrates, Vero cells [4], and stored in acceptable conditions. That was reassuring. Then I was baffled when I was told what I had to spend to have my sister treated: 150 \$ US for Rabies immunoglobulins (administrative fees included) and 40 \$US for each of the five vaccine injections as per the current national standards, the 'Essen' regimen [5]. Given

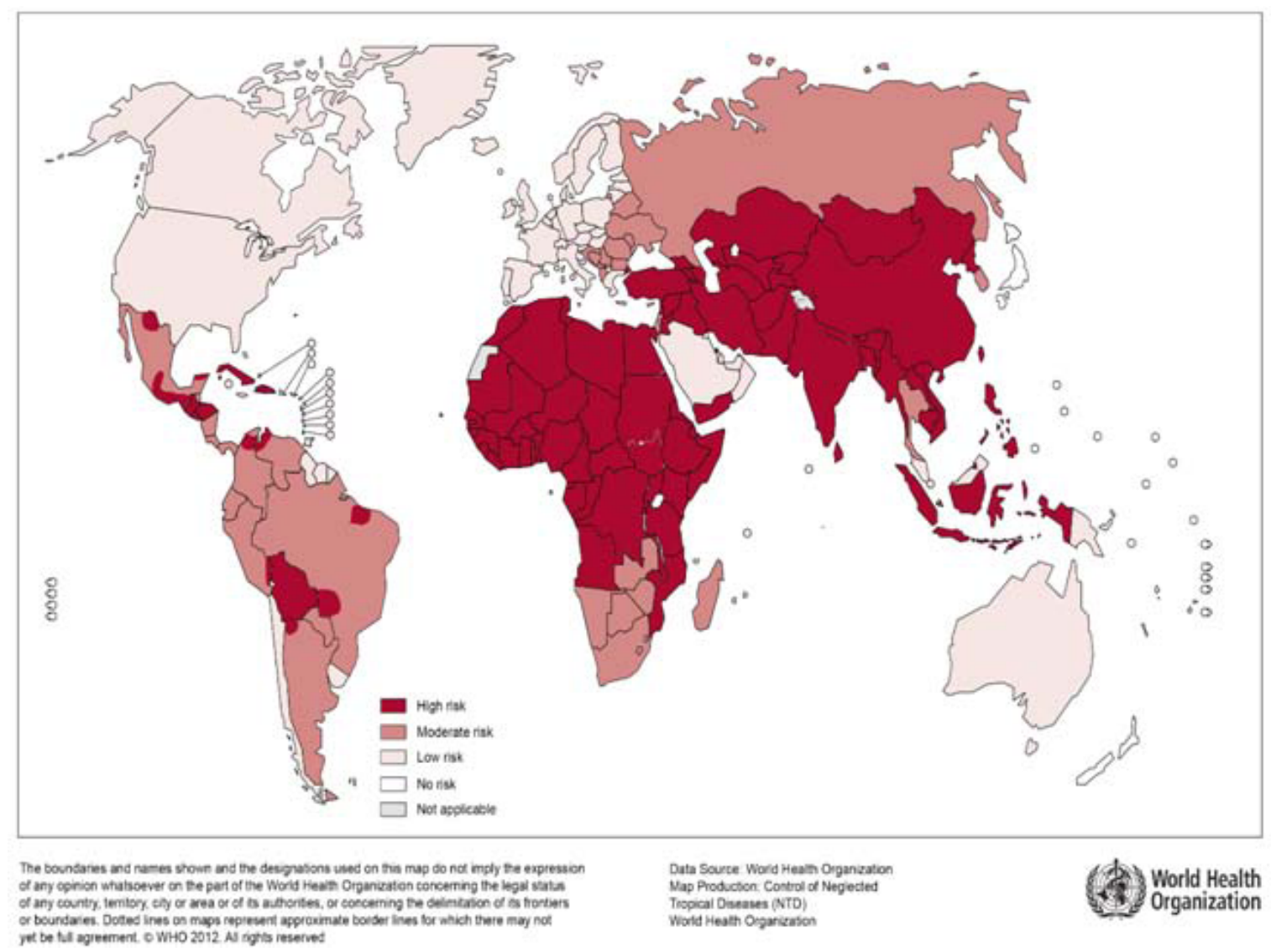

Figure 1: Distribution of risk levels for humans contacting rabies, worldwide, 2011. 
that the country ranks second to last on the Human Development Index (186 out of 187 countries), and its per capita income, which stood at $\$ 220$ in 2012, is among the lowest in the world [6], this is a scandal bearing in mind that Rabies is regarded as endemic in DR Congo.

I started to imagine the high number of dog bites that occur every day in Kinshasa alone (the city capital of DR Congo where I live), contrasting with the lack of a widespread national program to get domestic and stray dogs vaccinated. Adding to that what I had just discovered, the financial bottleneck to appropriate care once a person (a child most of the time) is bitten. Definitely, crossing fingers while anxiously counting the 10 days of the dog's observation period [7] should not be the only option. But how to find an innovative approach to fight Rabies in DR Congo without having trustworthy locally generated epidemiological data about Rabies in animal reservoirs (mainly dogs) and at least realistic statistics of Rabies incidence in humans.

Categorizing DR Congo as a country with highly endemic canine Rabies and dog-to-dog transmission, and human cases, though plausible, is based on data extrapolation from studies performed elsewhere and outstanding sporadic outbreaks that happened in a recent past. There is dying need to perform epidemiological studies that will assess the extent of the public health threat to put in place matching strategy to eliminate or at least dramatically reduce the burden of Rabies in the Democratic Republic of Congo. One can rightfully say the same about other vaccine-preventable diseases. International partnership, collaboration and support are much needed to help local initiatives reach that goal.

\section{References}

1. Maps of world. 07 February 2013. [Citation : 27 July 2015.]

2. Knobel DL, Cleaveland S, Coleman PG, Fèvre EM, Meltzer MI, Miranda $\mathrm{ME}$, et al. Re-evaluating the burden of rabies in Africa and Asia. Bull World Health Organ. 2005; 83(5):360-68.

3. Rupprecht CE, Hanlon CA, Hemachudha T. Rabies re-examined. Lancet Infect Dis. 2002; 2(6):327-43.

4. WHO Publication. Rabies vaccines: WHO position paper-recommendations. Vaccine. 2010; 28(44):7140-2. doi: 10.1016/j. vaccine.2010.08.082

5. WHO Expert Consultation on Rabies: second report (TRS : 982). WHO; 2013.

6. Democratic Republic of Congo/Overview. The World Bank, 07 April 2015.

7. Jackson AC. Rabies and Other Rhabdovirus Infections. In: Longo DL, et al. Harrison's Principles of Internal Medicine, 18th ed. New York: McGraw Hill Professional; 2012. 